\title{
Anterior ischaemic optic neuropathy. A correlative clinical and visual evoked potential study of 18 patients
}

\author{
PD THOMPSON, FL MASTAGLIA, WM CARROLL \\ From the Department of Neurology and University Department of Medicine, Queen Elizabeth II Medical Centre, \\ Perth, Western Australia
}

SUMMARY The clinical and visual evoked potential (VEP) findings were analysed in 18 patients with anterior ischaemic optic neuropathy. The VEP studies showed a variety of abnormalities which could be interpreted as being the result of subcomponent interaction consequent upon loss or attenuation of the normal macular-derived P $\overline{100}$ component. Delay of normal VEP subcomponents was not seen. The VEP findings were non-specific but pointed to a severe disturbance of transmission in optic nerve fibres subserving central vision. No significant changes were observed with time in most cases indicating a static monophasic process with no significant recovery.

The abrupt onset of visual loss in later life associated with pallid swelling of the optic disc characterises the clinical syndrome of anterior ischaemic optic neuropathy which has been the subject of recent reviews. ${ }^{12}$ The visual loss is invariably permanent, and a variety of field defects are seen, the most common being an altitudinal hemianopia or central scotoma. Both eyes may be involved sequentially, after intervals ranging from days to years. Most cases are idiopathic but occasional cases are due to temporal arteritis, $^{3}$ acute hypotension ${ }^{4-6}$ or migraine. ${ }^{7}$ Diabetes mellitus and hypertension are possible contributory factors in some idiopathic cases. ${ }^{18}$ Histologically, infarction with extensive axonal loss is found in the anterior portion of the optic nerve in the territory of the posterior ciliary arteries, the process being maximal at the optic nerve head in the region of the lamina cribrosa. ${ }^{9}$ In some cases, evidence of thrombosis has been found in the posterior ciliary arteries. ${ }^{3910}$ The reasons for the susceptibility of this site to infarction are incompletely understood. The importance of intraocular pressure in determining perfusion of the anterior portion of the optic nerve has been stressed by Hayreh, ${ }^{11}$ particularly in idiopathic anterior ischaemic optic neuropathy.

In contrast to demyelinating lesions, the physiological changes resulting from ischaemic lesions of

Address for reprint requests: Dr PD Thompson, Department of Neurology, Institute of Psychiatry, De Crespigny Park, Denmark Hill, London SE5 8AF, UK.

Received 9 November 1984 and in revised form 30 May 1985. Accepted 12 June 1985 the anterior visual pathway have received little attention. The few pattern VEP studies which have been reported have drawn attention to the reduction in response amplitude with preservation of normal latencies in the acute stages, ${ }^{1213}$ or unspecified "delay" of the VEP. ${ }^{14-16}$ There has been no sequential study of the VEP with the passage of time. In the present report the VEP and neuro-ophthalmic findings in the acute and chronic stages of anterior ischaemic optic neuropathy are described in 18 patients, in seven of whom follow-up studies were carried out.

\section{Patients and methods}

The 18 subjects comprised 11 males and seven females ranging from 53 to 81 years of age (mean 63 years). They were subdivided into the following three groups on the basis of the duration of the visual impairment (see also table 1).

(1) Acute anterior ischaemic optic neuropathy (7 cases) Acute onset of visual impairment in the preceding 2 weeks, with pallid disc oedema, with or without retinal haemorrhages. In two of the seven cases, the two eyes were involved in rapid succession.

(2) Acute-chronic bilateral anterior ischaemic optic neuropathy (2 cases) Acute monocular visual loss with disc appearances as above and a past history of a similar episode in the other eye.

(3) Chronic anterior ischaemic optic neuropathy (9 cases) A history of painless monocular visual loss of acute onset more than 2 months previously with subsequent optic atrophy, in the absence of other identifiable causes of optic nerve disease. Bilateral involvement was present in one of these cases.

Neuro-ophthalmic examination included measurement of visual acuity (Snellen Chart), tests of colour vision (Ishihara 
plates), mapping of the visual fields and ophthalmoscopy. None of the patients included had cataracts or retinal or macular disease. Pattern-reversal VEPs to monocular stimulation of the central-field ( $3^{\circ}$ radius, $12^{\prime}$ checks) were recorded using a technique which has been described elsewhere. ${ }^{1718}$ Monocular responses were recorded from an electrode at $\mathrm{Oz}(10-20$ system) referred to $\mathrm{Cz}$. In five patients (cases 3, 7, 13, 17 and 18), VEPs were also recorded to whole-field $\left(15^{\circ}\right.$ radius, $50^{\prime}$ checks), central-field ( $4^{\circ}$ radius, $20^{\prime}$ checks), vertical and/or horizontal hemi-field stimulation $\left(15^{\circ}\right.$ radius, $50^{\prime}$ checks) from a transverse and sagittal array of occipital electrodes. The transverse electrodes were positioned 5 and $10 \mathrm{~cm}$ to either side of a midline electrode $5 \mathrm{~cm}$ above the inion. Additional electrodes were placed at the inion and $7.5 \mathrm{~cm}$ above and $5 \mathrm{~cm}$ below this point. All electrodes were referred to $\mathrm{Fz}$. Where necessary, spectacles were worn during recordings to correct for errors of refraction. Normal limits for the P $\overline{100}$ latency $(<113 \mathrm{~ms})$ and amplitude $(>2 \mu \mathrm{V})$ for the single channel studies had previously been estimated in a group of 50 normal subjects aged 17 to 65 years $^{17}$ and values for the multichannel recordings were obtained from 27 normal subjects aged 21 to 59 years (normal whole-field $\mathrm{P} \overline{100}$ latency and amplitude were $<104 \mathrm{~ms}$ and $>4.6 \mu \mathrm{V}$ respectively). Typical whole-field and half-field responses from a normal subject are shown in fig 1 .

\section{Results}

\section{Clinical features}

The clinical details are summarised in table 1. The acute cases presented with a typical clinical profile. Progressive monocular visual loss was complete within 24 to 36 hours of onset, and in only one patient was there any subsequent improvement in visual acuity. Premonitory visual obscurations or scintillations were rare. Mild retro- and peri-orbital pain was

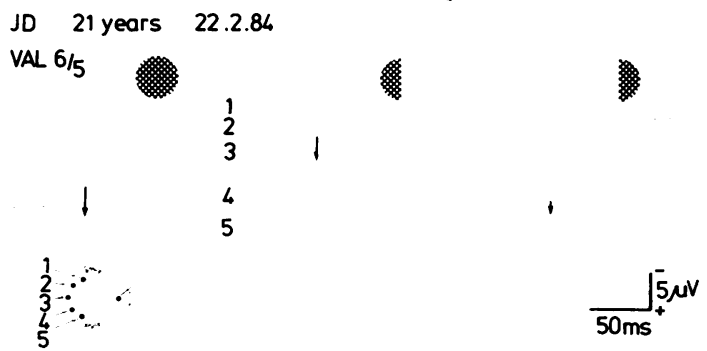

Fig 1 Monocular VEPs recorded to whole-field and nasal and temporal half-field pattern-reversal stimulation from $a$ normal subject. The whole-field $\left(15^{\circ}\right.$ radius, $50^{\prime}$ check) $P \overline{100}$ is symmetrically distributed about the mid-occipital channel, whereas to half-field stimulation this component has an asymmetrical topography. Note that the half-field macular derived ${ }^{2021} P \overrightarrow{100}$ component (arrow) is seen maximally over the scalp ipsilateral to the stimulated half-field thus being distinguished topographically from the complex of opposite polarity (that is paramacular derived) which is seen over the contralateral scalp. present in four of the idiopathic cases, contrasting with the more severe pain and scalp tenderness in the cases of anterior ischaemic optic neuropathy associated with temporal arteritis. Four patients developed bilateral anterior ischaemic optic neuropathy, sequential involvement of the two eyes occurring within days in two patients and after intervals of 9 months and 10 years in the remaining two. In only five patients was an aetiology identified. Cases 2, 6 and 7 had temporal arteritis, case 16 had tertiary syphilis, case 13 had Sjogren's syndrome and in case 11 , the anterior ischaemic optic neuropathy followed an episode of severe migraine. Of the 12 cases classified as idiopathic, four were hypertensive and two had suffered episodes of vertebrobasilar ischaemia. Visual acuity was reduced in the affected eyes in all patients except case 18 . The most common field defects were central scotomata (10 cases) and altitudinal hemianopias (six cases). Reduced visual acuity and dyschromatopsia correlated closely with the presence of central-field defects. Disc swelling and pallor characterised the acute stages, while in chronic cases the disc was pale and hypovascular.

\section{Single channel $V E P$ recordings}

Eleven eyes (cases 1-9) were first studied within 1 to 2 weeks of the onset of visual impairment (early cases). Twelve eyes (cases 8-18) were first studied in the chronic stage (late cases) at intervals ranging from 2 months to 10 years after the visual loss. The findings are summarised in tables 1 and 2 .

Early cases The VEPs were abnormal in each of the nine cases. In six of the 11 affected eyes, no response was recognisable. In the remaining five, a broad low amplitude positivity was recorded. In four of these, there was a single late positivity at $117 \mathrm{~ms}, 120 \mathrm{~ms}$, $138 \mathrm{~ms}$ and $142 \mathrm{~ms}$ (for example, fig 2). In the remaining case, the response comprised a broad low amplitude bifid positivity made up of an initial positivity at $100 \mathrm{~ms}$ merging with a later component at $114 \mathrm{~ms}$.

Late cases Identifiable responses were present in nine of the 12 affected eyes. Two displayed broad bifid positive complexes with an attenuated initial positivity merging with a later positive component of larger amplitude at $126 \mathrm{~ms}$ and $130 \mathrm{~ms}$. Five eyes displayed a single broad late positivity at 118, 126, 129, 137 and $155 \mathrm{~ms}$. The remaining two eyes (case 18, who had a bilateral superior altitudinal hemianopia) showed responses of normal latency and morphology. Asymptomatic eyes of the 13 cases with unilateral anterior ischaemic optic neuropathy, clinical and VEP examinations of the unaffected eye was normal in 10. The VEP was abnormal in case 12 due to longstanding strabismic amblyopia. In cases 4 and 7 there was an asymptomatic delay of the $\mathrm{P} \overline{\mathbf{1 0 0}}$ component in the unaffected eye (124 ms in case $4,128 \mathrm{~ms}$ in case 7 ). 
Table 1 Details of clinical and VEP findings in the 18 cases of anterior ischaemic optic neuropathy

\begin{tabular}{|c|c|c|c|c|c|c|c|c|c|c|c|}
\hline & Case & $\begin{array}{l}\text { Age } \\
(y r)\end{array}$ & Sex & Aetiology & $\begin{array}{l}\text { Eye } \\
\text { affected }\end{array}$ & $\begin{array}{l}\text { Interocular } \\
\text { interval }\end{array}$ & $\begin{array}{l}\text { Visual } \\
\text { acuity }\end{array}$ & $\begin{array}{l}\text { Colour } \\
\text { vision }\end{array}$ & $\begin{array}{l}\text { Field } \\
\text { defect }\end{array}$ & $\begin{array}{l}\text { Disc } \\
\text { appearance }\end{array}$ & $V E P^{*}$ \\
\hline \multicolumn{12}{|l|}{ I ACUTE } \\
\hline \multirow[t]{3}{*}{ Bilateral } & 1 (EM) & 54 & $\mathbf{M}$ & AION & $\mathbf{R}$ & Days & $6 / 18$ & $\mathbf{A}$ & CS & IP & $\begin{array}{l}\text { Broad low ampl. late } \\
\text { pos. (P120) }\end{array}$ \\
\hline & & & & & $\mathbf{L}$ & & $6 / 12$ & $\mathbf{A}$ & CS & IP & Broad low ampl. bifa \\
\hline & 2 (RA) & 83 & $\mathbf{M}$ & GCA & $\begin{array}{l}\mathbf{R} \\
\mathbf{L}\end{array}$ & 2 weeks & $\begin{array}{l}\text { CF } \\
6 / 60\end{array}$ & $\begin{array}{l}\mathbf{A} \\
\mathbf{A}\end{array}$ & $\begin{array}{l}\text { CS } \\
\text { CS }\end{array}$ & IP & $\begin{array}{l}\text { Absent } \\
\text { Absent }\end{array}$ \\
\hline \multirow[t]{4}{*}{ Unilateral } & 3 (HS) & 61 & $\mathbf{F}$ & AION & $\mathbf{R}$ & & $6 / 36$ & A & IAH & IP & $\begin{array}{l}\text { Broad low ampl. late } \\
\text { pos. (P117) }\end{array}$ \\
\hline & $4(\mathrm{WD})$ & 67 & $\mathbf{M}$ & AION & $\mathbf{R}$ & & $6 / 12$ & $\mathbf{A}$ & CS & IP & $\begin{array}{l}\text { Late low ampl. pos. } \\
\text { (P142) }\end{array}$ \\
\hline & $5(\mathrm{CP})$ & 68 & $\mathbf{M}$ & AION & $\mathbf{L}$ & & CF & $\mathbf{A}$ & CS & IP & $\begin{array}{l}\text { Late low ampl. pos:으 } \\
\text { (P138) }\end{array}$ \\
\hline & $\begin{array}{l}6 \text { (LR) } \\
7 \text { (PS) }\end{array}$ & $\begin{array}{l}74 \\
71\end{array}$ & $\begin{array}{l}\mathbf{F} \\
\mathbf{M}\end{array}$ & $\begin{array}{l}\text { GCA } \\
\text { GCA }\end{array}$ & $\begin{array}{l}\mathbf{L} \\
\mathbf{R}\end{array}$ & & $\begin{array}{l}6 / 18 \\
\text { HM }\end{array}$ & $\begin{array}{l}\mathbf{A} \\
\mathbf{A}\end{array}$ & $\begin{array}{l}\text { CS } \\
\text { CS }\end{array}$ & $\begin{array}{l}\text { IP } \\
\text { IP }\end{array}$ & $\begin{array}{ll}\text { Absent } & \bar{\sigma} \\
\text { Absent } & \overline{\bar{\sigma}}\end{array}$ \\
\hline \multirow[t]{2}{*}{$\begin{array}{l}\text { II ACUTE/ } \\
\text { CHRONIC }\end{array}$} & $8(\mathrm{LW})$ & 62 & $\mathbf{F}$ & AION & $\begin{array}{l}\mathbf{R} \\
\mathbf{L}\end{array}$ & 9 months & $\begin{array}{l}6 / 24 \\
6 / 9\end{array}$ & $\mathbf{A}$ & $\begin{array}{l}\text { IAH } \\
\text { IAH }\end{array}$ & $\begin{array}{l}\text { IP } \\
\text { OA }\end{array}$ & $\begin{array}{l}\text { Absent } \\
\text { Absent }\end{array}$ \\
\hline & 9 (KS) & 75 & $\mathbf{M}$ & AION & $\begin{array}{l}\mathbf{L} \\
\mathbf{R}\end{array}$ & 10 years & $\begin{array}{l}6 / 12 \\
6 / 18\end{array}$ & $\mathbf{A}$ & $\begin{array}{l}\text { IAH } \\
\text { IAH }\end{array}$ & $\begin{array}{l}\text { IP } \\
\text { OA }\end{array}$ & $\begin{array}{l}\text { Absent } \\
\text { Low ampl. late pos. } \\
\quad \text { (P1 18) }\end{array}$ \\
\hline \multirow{6}{*}{$\begin{array}{l}\text { III CHRONIC } \\
\text { Unilateral }\end{array}$} & & & & & & & & & & & \\
\hline & $\begin{array}{l}10(\mathrm{BD}) \\
11(\mathrm{~PB}) \\
12(\mathrm{JB})\end{array}$ & $\begin{array}{l}66 \\
60 \\
65\end{array}$ & $\begin{array}{l}\mathbf{F} \\
\mathbf{F} \\
\mathbf{M}\end{array}$ & $\begin{array}{l}\text { AION } \\
\text { Migraine } \\
\text { AION }\end{array}$ & $\begin{array}{l}\mathbf{R} \\
\mathbf{R} \\
\mathbf{L}\end{array}$ & & $\begin{array}{l}6 / 9 \\
6 / 60 \\
6 / 18\end{array}$ & $\begin{array}{l}\mathbf{A} \\
\mathbf{A}\end{array}$ & $\begin{array}{l}\text { Constricted } \\
\text { Quadrantic } \\
\text { CS }\end{array}$ & $\begin{array}{l}\text { OA } \\
\text { OA } \\
\text { OA }\end{array}$ & $\begin{array}{l}\text { Late pos. (P156) } \\
\text { Absent } \\
\text { Broad low ampl. bif } \\
\quad \text { pos. }\end{array}$ \\
\hline & 13 (PW) & 53 & $\mathbf{F}$ & Sjögren's & $\mathbf{R}$ & & $6 / 12$ & $\mathbf{A}$ & IAH & OA & $\begin{array}{l}\text { Broad, bifid low am } \\
\text { pos. }\end{array}$ \\
\hline & 14 (AP) & 58 & $\mathbf{M}$ & AION & $\mathbf{R}$ & & CF & $\mathbf{A}$ & IAH & OA & $\begin{array}{l}\text { Late low ampl. pos. } \\
\text { (P137) }\end{array}$ \\
\hline & $\begin{array}{l}15(\mathrm{MD}) \\
16(\mathrm{TH})\end{array}$ & $\begin{array}{l}63 \\
61\end{array}$ & $\begin{array}{l}\mathbf{F} \\
\mathbf{M}\end{array}$ & $\begin{array}{l}\text { AION } \\
\text { Syphilis }\end{array}$ & $\begin{array}{l}\mathbf{L} \\
\mathbf{R}\end{array}$ & & $\begin{array}{l}6 / 60 \\
6 / 18\end{array}$ & $\begin{array}{l}\mathbf{A} \\
\mathbf{A}\end{array}$ & $\begin{array}{l}\text { CS } \\
\text { CS }\end{array}$ & $\begin{array}{l}\text { OA } \\
\text { OA }\end{array}$ & $\begin{array}{l}\text { Absent } \\
\text { Late low ampl. pgs. } \\
\text { (P126) }\end{array}$ \\
\hline & 17 (JT) & 58 & $\mathbf{M}$ & AION & $\mathbf{L}$ & & $6 / 18$ & $\begin{array}{l}\text { Normal } \\
\text { (slow) }\end{array}$ & $\begin{array}{l}\text { Relative } \\
\text { Inferior } \\
\text { arcuate } \\
+\mathrm{CS}\end{array}$ & OA & 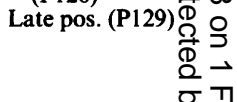 \\
\hline Bilateral & $18(\mathrm{CF})$ & 77 & $\mathbf{M}$ & AION & $\begin{array}{l}\mathbf{R} \\
\mathbf{L}\end{array}$ & Days & $\begin{array}{l}6 / 5 \\
6 / 5\end{array}$ & $\mathbf{A}$ & $\begin{array}{l}\text { SAH } \\
\text { SAH }\end{array}$ & $\begin{array}{l}\text { Bilat. } \\
\text { inferior } \\
\text { disc pallor }\end{array}$ & $\begin{array}{l}\text { Normal } \\
\text { Normal }\end{array}$ \\
\hline
\end{tabular}

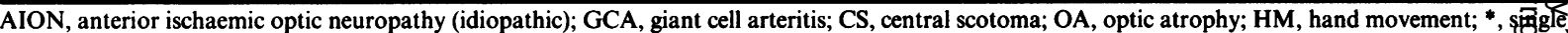
channel recording; IP, ischaemic papilloedema; IAH, inferior altitudinal hemianopia; SAH, superior altitudinal hemianopia; A, absent.

\section{Multi-channel $V E P$ recordings}

Five patients had VEPs recorded to whole-field and half-field stimulation (table 2). Four of the five had monocular visual impairment, while the fifth (case 18) had a bilateral superior altitudinal hemianopia without impairment of visual acuity. The whole-field responses were normal in case 18 but were abnormal from the symptomatic eyes in the other four patients, being absent in one (case 7) and comprising a bifid (case 13) or single late positivity (cases 3 and 17) in the others (for example fig 3A). Vertical half-field studies showed that these abnormalities were the result of a combination of attenuated macular-derived $\mathrm{P} \overline{\mathbf{1 0 0}}$ components and dominant paramacular-derived P135 components consequent upon the loss of the P100 component from the nasal and temporal halffield. The summation of these altered half-field VEPs was responsible for the abnormal whole-field waveform, that is bifid or late positivities (for example fig $3 \mathrm{~A}$ ). The latencies of the half-field subcomponents
$(\mathrm{P} \overline{100}$ and $\mathrm{P} \overline{135})$ from these patients were all normal. Selective involvement of parts of the superior and inferior half-fields was also demonstrated in three of the four patients who had superior and inferior halffield VEPs recorded (for example see fig 3B). Case 18 showed absent (right eye) and attenuated (left eye) responses only to superior half-field stimulation. Central-field ( $4^{\circ}$ radius, $20^{\prime}$ check) recordings from cases 3 and 17 did not add any further information, other than confirming selective involvement of fibres subserving central vision in case 17 , and showed comparable mid-occipital waveforms to those recorded to whole-field $\left(15^{\circ}\right.$ radius, $50^{\prime}$ check) stimulation.

These results were in good agreement with the visual field defects. Case 18 with bilateral superior altitudinal hemianopia demonstrated attenuated and absent superior half-field responses from the left and right eyes respectively, but normal inferior half-field and nasal and temporal half-field responses. In case 13 who had a right inferior altitudinal defect extend- 
Table 2 Summary of VEP findings in the five patients studied by multichannel recordings

\begin{tabular}{|c|c|c|c|c|c|c|c|}
\hline Case & $\begin{array}{l}\text { Symptomatic } \\
\text { eye }\end{array}$ & $\begin{array}{l}\text { Central } \\
\text { field }\end{array}$ & Whole-field & $\begin{array}{l}\text { Temporal } \\
\text { half-field }\end{array}$ & $\begin{array}{l}\text { Nasal } \\
\text { half-field }\end{array}$ & $\begin{array}{l}\text { Superior } \\
\text { half-field }\end{array}$ & $\begin{array}{l}\text { Inferior } \\
\text { half-field }\end{array}$ \\
\hline $\begin{array}{l}3 \text { (HS) } \\
7 \text { (PS) } \\
13 \text { (PW) } \\
17 \text { (JT) } \\
18 \text { (CF) }\end{array}$ & $\begin{array}{l}\text { RE } \\
\text { RE } \\
\text { RE } \\
\text { LE } \\
\text { RE } \\
\text { LE }\end{array}$ & $\begin{array}{l}\text { Late pos. } \\
\frac{-}{-} \\
\frac{-}{-}\end{array}$ & $\begin{array}{l}\text { Late pos. } \\
\text { A } \\
\text { Bifid pos. } \\
\text { Late pos. } \\
\text { N } \\
\text { N }\end{array}$ & $\begin{array}{l}\text { Att. P } \overline{100} \\
\text { P } \overline{135} \\
\text { P } 135 \\
\text { P } \overline{135} \\
- \\
-\end{array}$ & $\begin{array}{l}\text { P } \overline{135} \\
\text { P135 } \\
\text { Att. P } \overline{100} \\
\text { Att. P } \overline{100} \\
-\end{array}$ & $\begin{array}{l}\mathrm{N} \\
\mathrm{P} \overline{135} \\
\mathrm{~N} \\
\frac{\mathrm{A}}{\text { Att. }}\end{array}$ & $\begin{array}{l}\mathrm{P} \overline{135} \\
\mathrm{~A} \\
\text { Att. P } \overline{100} \\
\overline{\mathrm{N}} \\
\mathrm{N}\end{array}$ \\
\hline
\end{tabular}

$\mathrm{N}$, normal P $\overline{100} ; \mathrm{A}$, absent response; Att., attenuated; Pos., positivity.

ing into the superior temporal field (fig 3C), the inferior half-field response was attenuated and there was almost complete loss of the P100 component from the temporal half-field of this eye, with a dominant late positivity (P135) with a different topography to the P100 (cf fig 1). In case 17, who had a central scotoma with a relative inferior arcuate scotoma, the wholefield response from the left eye comprised a single late positivity which, with half-field stimulation, was seen to be arising from the paramacular regions of the temporal half-field. A residual nasal half-field $P 100$ component was present but did not contribute appreciably to the whole-field response.

HS $\$ 61$ years $\quad 30.9 .80$
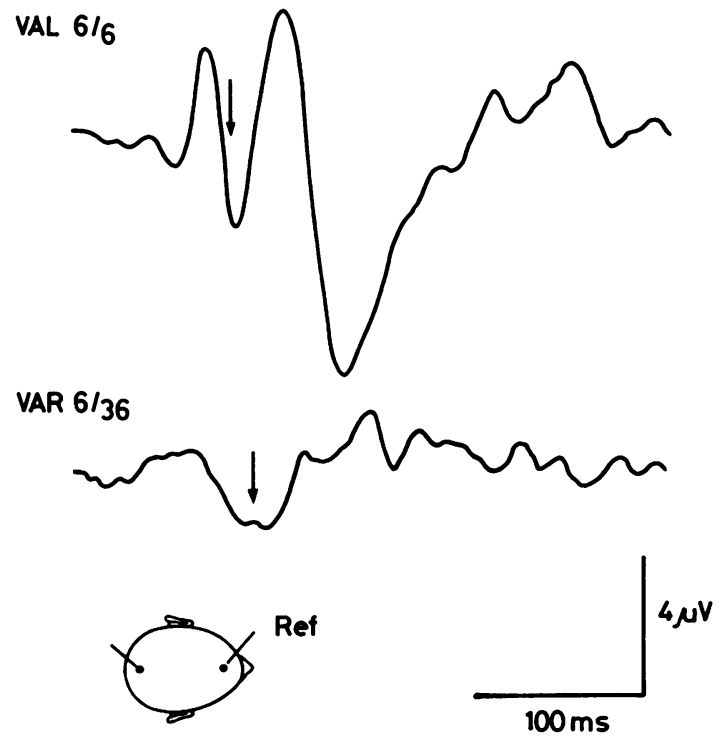

Fig 2 Monocular single-channel mid-occipital VEPs to central-field stimulation ( $3^{\circ}$ radius, $12^{\prime}$ check) recorded from a 61-year-old female (case 3, see table 1) with a one week history of abrupt painless loss of vision in the right eye resulting in a visual acuity of $6 / 36$ and an inferior altitudinal hemianopia. The VEP from this eye comprised at attenuated broadened late positivity (latency $117 \mathrm{~ms}$ ) compared to a normal VEP from the left eye (latency $97 \mathrm{~ms}$ ).

\section{Follow-up examinations}

In seven patients, VEPs were recorded on a second occasion after intervals of 3 to 52 months (table 3 ). In three patients (cases 3,4 and 7) the initial VEP study was performed less than 2 weeks after the onset of visual impairment. In case 3 the first VEP showed a low amplitude late positivity $(117 \mathrm{~ms})$ and a follow-up study after 32 months showed only improved definition of this positivity which was demonstrated to be of paramacular origin (P135) by the multichannel half-field recordings. In cases 4 and 7 the follow-up study after intervals of 6 and 3 months respectively, showed no changes. In the other four cases, the initial study was performed 3 months or longer after the onset of visual impairment. In three of these (cases 16, 17 and 18), follow-up recordings after 17,4 and 12 months, respectively showed no change (for example fig $4 \mathrm{~A}$ and $\mathrm{B}$ ). In the remaining case (13), the follow-up study after 52 months showed increased amplitude and improved definition of the previously recorded bifid positivity. Thus, five of the seven cases showed no change, while in two there was some improvement in the definition of the abnormal waveforms.

\section{Discussion}

Characteristic patterns of VEP abnormality have been identified in demyelinating, heredodegenerative, compressive and toxic optic neuropathies by analysis of the behaviour of the half-field VEP sub-components, in addition to the latency of the principal full-field components. ${ }^{19-22}$ In the present study of anterior ischaemic optic neuropathy, the VEP findings exhibited characteristic and enduring patterns of abnormality which correlated with the extent of visual impairment and the type of visual field defect. Typically, monocular VEPs from symptomatic eyes showed either low amplitude bifid or late single positivities, or positivities at normal latency but of reduced amplitude. Half-field stimulation in representative patients with central or altitudinal field defects illustrated that the monocular waveform changes were the result not of P100 delays, as in demyelinating optic neuropathy, but rather of com- 
(b)

VAL $6 / 5$

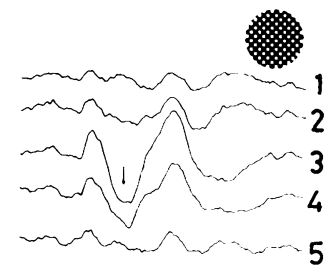

VAR $6 / 12$
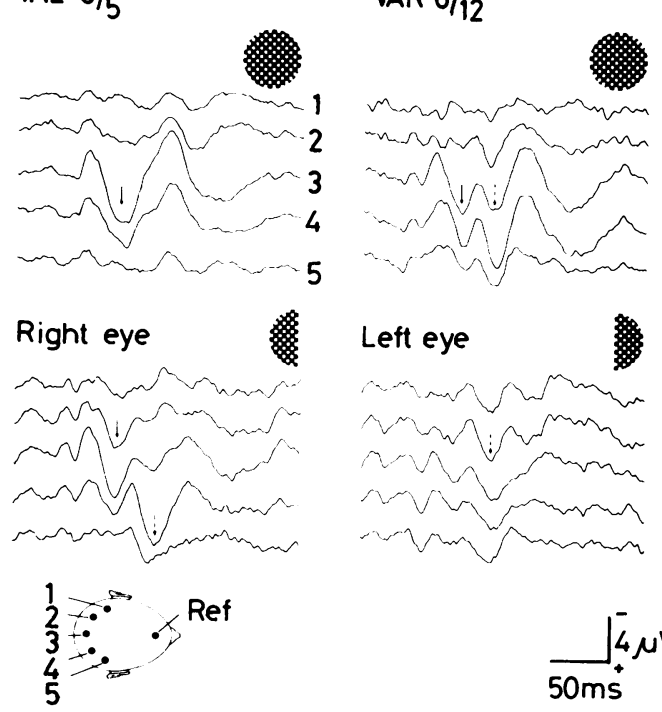

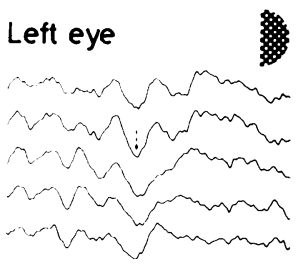

$\underset{50 \mathrm{~ms}}{\overline{4}} \mu \mathrm{V}$
Left eye

Right eye
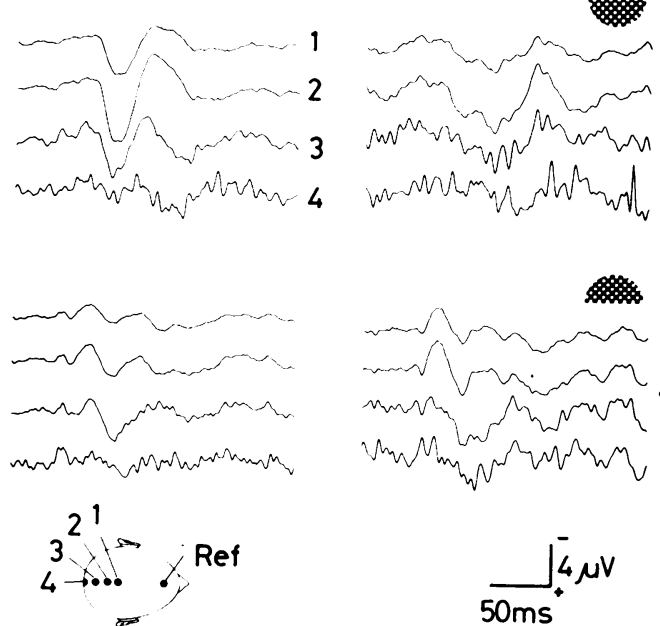

(c)

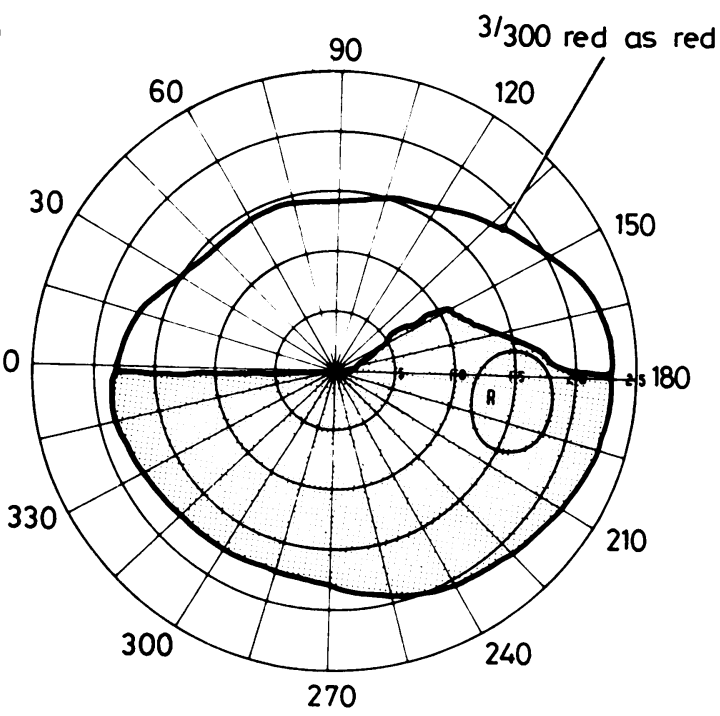

Fig 3 Multi-channel VEPs to monocular whole-field and half-field ( $15^{\circ}$ radius, $50^{\prime}$ check) stimulation recorded from case 13 , a 58-year-old female who experienced an abrupt onset of visual impairment in the right eye 2 years earlier. (A) Normal whole-field VEP from the left eye ( $P 100$ latency, $91 \mathrm{~ms}$ ) compared to a bifid positivity (latencies $89 \mathrm{~ms}$ and $120 \mathrm{~ms}$ ) from the right eye. The right eye half-field VEPs illustrate a preserved macular-derived PI00 component (solid arrow) and a prominent paramacular P135 component (broken arrow) from the nasal half-field, while the temporal half-field response comprised a widely distributed paramacular P $\overline{135}$ (broken arrow) only. (B) Attenuated broadened bifid positivity recorded from the right eye to inferior half-field stimulation compared to a normal response from the left eye. Note the relative preservation of the superior half-field VEP from the right eye and the relative prominence of the inferior half-field response from the normal left eye. (C) Central visual field plot from the right eye showing a relative inferior altitudinal hemianopia extending into the superior temporal quadrant which correlates with the VEP findings above [( $A)$ and $(B)]$. 
Table 3 Summary of VEP findings in the seven patients who had follow-up studies

\begin{tabular}{|c|c|c|c|c|}
\hline Case & Time to first $V E P$ & First $V E P$ & $\begin{array}{l}\text { Interval between first and } \\
\text { second VEP }\end{array}$ & Change \\
\hline $\begin{array}{l}3 \text { (HS) } \\
4 \text { (HD) } \\
7 \text { (PS) } \\
13 \text { (PW) } \\
16 \text { (TH) } \\
17(\mathrm{JT}) \\
18 \text { (CF) }\end{array}$ & $\begin{array}{l}<1 \text { wk. } \\
<2 \text { wk. } \\
<1 \text { wk. } \\
24 \text { mth. } \\
60 \text { mth. } \\
3 \text { mth. } \\
3 \text { mth. }\end{array}$ & $\begin{array}{l}\text { Late pos. } \\
\text { Late pos. } \\
\text { Absent } \\
\text { Bifid pos. } \\
\text { Late pos. } \\
\text { Late pos. } \\
\text { Normal }\end{array}$ & $\begin{array}{l}32 \mathrm{mth} . \\
6 \mathrm{mth} . \\
3 \mathrm{mth} . \\
52 \mathrm{mth} . \\
17 \mathrm{mth} . \\
4 \mathrm{mth} . \\
12 \mathrm{mth} .\end{array}$ & $\begin{array}{l}\text { Improved definition } \\
\text { None } \\
\text { None } \\
\text { Improved definition/amplitude } \\
\text { None } \\
\text { None } \\
\text { None }\end{array}$ \\
\hline
\end{tabular}

pos. = positivity.
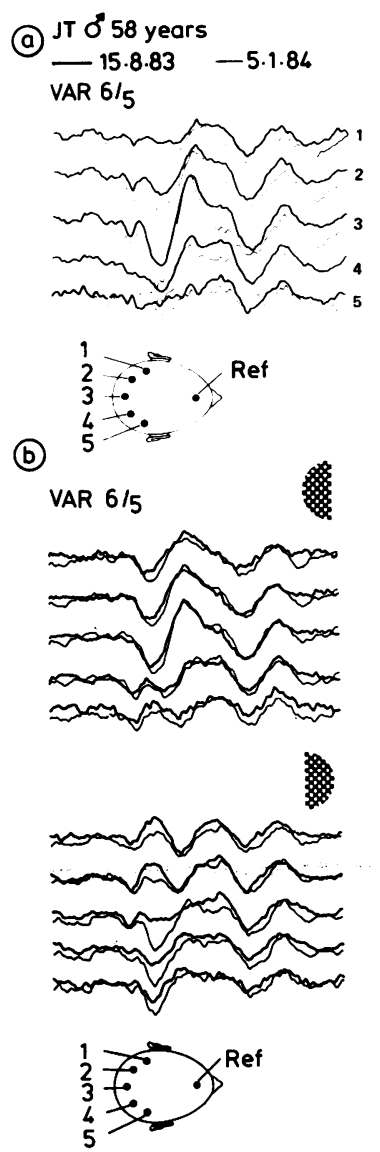

Fig 4 Serial monocular whole-field VEPs from the right and left eyes $(A)$ and half-field VEPs from the left eye $(B)$ recorded over an interval of 4 months from case $17, a$ 58-year-old male who experienced abrupt painless left monocular loss of vision 3 months prior to the first recording. The broad low amplitude late positivity (latency $129 \mathrm{~ms}$ ) to whole-field stimulation from the left eye remained essentially unchanged over the 4 month period as did the half-field responses from this eye. The right eye whole-field $P \overline{100}$ latency was $94 \mathrm{~ms}$. plete or partial substitution of the paramacular P $\overline{135}$ subcomponent for the usually dominant macularderived P100 component ${ }^{202324}$ (for example fig 3A). These changes were seen in the acute stages of the condition and were found to persist for long periods in patients who were studied serially.

In previous studies of the VEP in anterior ischaemic optic neuropathy, macular and paramacular subcomponents were not identified and as a result, there have been various interpretations of the findings. Glaser and Laflamme ${ }^{13}$ in a study of 35 patients examined in either the acute or chronic stages, found a prolongation of the latency of the major positivity in many of the acute cases and a low amplitude positivity of normal latency in the majority of chronic cases. They concluded that the combination of a major positive component of normal or mildly prolonged latency but of low amplitude, was a possible indicator of anterior ischaemic optic neuropathy. Others have also noted the occurrence of late positivities to pattern reversal stimulation ${ }^{1214-16}$ and the studies of Ellenberger and Ziegler ${ }^{25}$ and Harding $e t a l^{26}$ showed mild latency prolongation and amplitude reduction to flash (luminance) stimulation. The extent of the latency increases reported in these studies was relatively small when compared to those found in demyelinating optic neuropathy. In the study by Wilson, ${ }^{12}$ who used both flash and pattern VEPs, the most characteristic change found was a marked reduction in response amplitude. It is likely that the mid-occipital positivities recorded in these studies were not homogeneous but represented varying combinations of macular $(\mathbf{P} 100)$ and paramacular (P135) positivities.

The mid-occipital waveforms recorded to centralfield and whole-field stimulation in the present study were comparable and, in some respects, resembled those described in the above reports. The two basic patterns of abnormal waveforms comprised either a bifid positivity or a single late positivity. Half-field recordings showed that the later positivity in both was of paramacular origin, conforming to the P135 component, ${ }^{23}$ while the earlier positivity in the bifid response was of macular origin (that is P100 com- 
ponent). Analysis of the visual field defect in patients who had half-field studies showed that, where there was some sectorial or altitudinal sparing of the central field, a macular derived P100 component of normal latency was recorded when the stimulated half-field included the preserved area of the central field. In contrast, when the stimulated half-field incorporated the affected area of the central field, no response or only paramacular-derived components (that is P135) were recorded depending on the size of the central scotoma.

The finding of normal whole-field, half-field and central-field VEPs in the patient with superior altitudinal hemianopia (case 18) is at first sight surprising in view of the marked changes found in patients with inferior altitudinal hemianopia. The explanation probably lies in the fact that the visual cortex to which the superior half-field projects, lies below the calcarine fissure on the infero-medial surface of the occipital lobe and is therefore distant from the recording electrodes, whereas the cortex representing the inferior half-field, is superiorly positioned and therefore closer to the recording electrodes. Thus, the whole-field and half-field VEPs arise principally from cortex representing the inferior visual field..$^{24} 27$ Of interest also was the observation of late positivities from the asymptomatic eye of two patients (cases 4 and 7) and in one (case 7) the half-field studies confirmed the change was due to P100 delay. In neither patient was there any clinical neuro-ophthalmic abnormality so that it is likely that the VEP changes may represent subclinical involvement, given the high frequency of sequential bilateral optic neuropathy in this condition. ${ }^{2}$

In conclusion, a number of abnormal VEP patterns may be found in anterior ischaemic optic neuropathy. These correlate with the type of visual field defect in individual patients and are stable over long periods. Late or bifid positivities occur frequently and represent the emergence of or unmasking of normal latency paramacular subcomponents consequent upon the loss or attenuation of normal macular subcomponents, rather than resulting from slowed conduction through affected fibres.

The authors thank Drs JL Black and DW Collins in whose laboratory some of the early VEP studies were performed, Miss Jennie Davies for technical assistance with the multichannel recordings and Mrs P McBryde for preparation of the manuscript.

\section{References}

${ }^{1}$ Boghen DR, Glaser JS. Ischaemic optic neuropathy: the clinical profile and natural history. Brain 1975; 98:689-708.
${ }^{2}$ Hayreh SS. Anterior ischaemic optic neuropathy. Arch $\underline{\overline{0}}$ Neurol 1981;38:675-8.

${ }^{3}$ McLeod D, Ojie E, Kohner EM, Marshall J. Fundus signs in temporal arteritis. $\mathrm{Br} J$ Ophthamol 1978;62:591-4.

${ }^{4}$ Drance SM, Morgan RW, Sweeney VP. Shock induced optic neuropathy: a cause of nonprogressive glaucoma $N$ Eng J Med 1973;288:392-5.

${ }^{5}$ Rootman J, Butler D. Ischaemic optic neuropathy-a combined mechanism. Br J Ophthalmol 1980;64:옹 826-31.

${ }^{6}$ Sweeney PJ, Breuer AC, Selhorst JB, Waybright EA $\stackrel{\underset{2}{\Sigma}}{<}$ Furlan AJ, Lederman RJ, Hanson MR, Tomsak R. Ischaemic optic neuropathy: a complication of cardio- 2 ? pulmonary bypass surgery. Neurology (NY) 1982;0 32:560-2.

${ }^{7}$ McDonald WI, Sanders D. Migraine complicated by $\frac{\bar{\sigma}}{\bar{\omega}}$ ischaemic papillopathy. Lancet 1971;2:521-3.

${ }^{8}$ Ellenberger C, Keltner JL, Burke RM. Acute optic neuropathy in older patients. Arch Neurol 1973;28:182-5. ڤ

${ }^{9}$ Henkind P, Charles NC, Pearson J. Histopathology of $\overrightarrow{ }$ ischaemic optic neuropathy. Am J Ophthalmol 1970; 69:78-90.

${ }^{10}$ Lieberman MF, Abbas S, Green WR. Embolic ischaemic $\vec{\omega}$ optic neuropathy. Am J Ophthalmol 1978;86:206-10.

${ }^{11}$ Hayreh SS. Pathogenesis of visual field defects: role of the ciliary circulation. Br J Ophthalmol 1970;54:289-311.

${ }^{12}$ Wilson WB. Visual evoked response differentiation of ischaemic optic neuritis from the optic neuritis of multiple sclerosis. Am J Ophthalmol 1978;86:530-5.

${ }^{13}$ Glaser JS, Laflamme P. The visual evoked respons methodology and application in optic nerve disease In: Thompson HS, ed. Topics in Neuro-ophthalmology.Baltimore: Williams and Wilkins, 1979:199-218.

${ }^{14}$ Asselman P, Chadwick DW, Marsden CD. Visual evokgdo responses in the diagnosis and management of patieg st suspected of multiple sclerosis. Brain 1975;98:261-82

${ }^{15}$ Hennerici M, Wenzel D, Freund HJ. The comparisong small size rectangle and checkerboard stimulation for the evaluation of delayed visual evoked responses in. patients suspected of multiple sclerosis. Brain 1977; 100:119-36.

${ }^{16}$ Halliday AM, Mushin J. The visual evoked potential in neuro-ophthalmology. In: Sokol S, ed. Internationa Ophthalmology Clinics, Vol 20 (1): Electrophysiology용 and Psychophysics: Their use in Ophthalmic Diagnosis.으 Boston: Little Brown, 1980:155-83.

${ }^{17}$ Collins DWK, Black JL, Mastaglia FL. Pattern reversal ${ }_{3}$ visual evoked potential: method of analysis and results in multiple sclerosis. $J$ Neurol Sci 1978;36:83-95.

${ }^{18}$ Carroll WM, Mastaglia FL. Leber's optic neuropathy: aclinical and visual evoked potential study of affected $\overline{\bar{J}}$ and asymptomatic members of a six generation family:? Brain 1979;102:559-80.

${ }^{19}$ Carroll WM, Kriss A, Baraitser M, Barrett G, Halliday. AM. The incidence and nature of visual pathway involvement in Friedreich's ataxia: a clinical and visual 3 evoked potential study of 22 patients. Brain 1980;
103:413-34.

${ }^{20}$ Carroll WM, Halliday AM, Kriss A. Improvements in the accuracy of pattern visual evoked potentials in the diagnosis of visual pathway disease. Neuro-ophthalmology 1982;2:237-53. 
${ }^{21}$ Halliday AM. The VEP in the investigation of diseases of the eye. In: Halliday AM, ed. Evoked Potentials in Clinical Testing. Edinburgh: Churchill Livingstone, 1982:149-85.

${ }^{22}$ Pullan PT, Carroll WM, Chakera T, Khangure M, Vaughan RJ. Management of extra-sellar pituitary tumours with bromocriptine: comparison of prolactin secreting and non-functioning tumours using half-field visual evoked potentials and high resolution computerised tomography. Aust NZ J Med 1985;15:303-8.

${ }^{23}$ Blumhardt LD, Barrett G, Halliday AM, Kriss A. The effect of experimental scotoma on the ipsilateral and contralateral response to pattern reversal in one half field. Electroencephalogr Clin Neurophysiol 1978;45: 376-92.
${ }^{24}$ Halliday AM, Barrett G, Halliday E, Michael WF. The topography of the pattern evoked potential. In: Desmedt JE, ed. New Developments in Visual Evoked Responses in the Human Brain. London: Oxford University Press, 1977:121-33.

${ }^{25}$ Ellenberger C, Ziegler SB. Visual evoked potentials and quantitative perimetry in multiple sclerosis. Ann Neurol 197\%;1:561-4.

${ }^{26}$ Harding GFA, Crews SJ, Good PA. The VEP in neuroophthalmic disease. In: Barber C, ed. Evoked Potentials. Lancaster: MTP Press, 1980:235-41.

${ }^{27}$ Kriss A, Halliday AM. A comparison of occipital potentials evoked by pattern onset, offset and reversal by movement. In: Barber C, ed. Evoked Potentials. Lancaster: MTP Press, 1980:205-12. 